\title{
Primary central nervous system lymphoma (PCNSL)
}

\section{Linfoma primário do sistema nervoso central}

Elizabete Maria Pereira de Andrade Caires ${ }^{1}$, Fernando Freua ${ }^{2}$, Felipe D’Almeida Costa ${ }^{3}$, Fernanda Lemos Moura ${ }^{1}$, Marcos Aurélio Peterlevitz², Antônio Alberto Zambon²

Primary Central Nervous System Lymphoma (PCNLS), an uncommon variant of extranodal non-Hodgkin lymphoma, involves brain, leptomeninges, eyes or spinal cord ${ }^{1}$.

A 63-year-old man with two months of cognitive impairment was submitted to brain MRI that revealed a expansive lesion in corpus callosum (Figure 1A and 1B). Biopsy was performed and histopathology showed a diffuse large-B-cell lymphoma
(Figure 2). Cytarabine, metrotrexate and rituximab ${ }^{2}$ was performed and after two months, patient returns to the emergency with cerebelar ataxia and somnolence. New brain MRI detected disease progression. Brain radiotherapy was indicated with additional boost of radiotherapy to the tumor bed. After 1 month, patient evolved with seizure and a lumbar puncture revealed meningeal dissemination. It was decided palliative care.

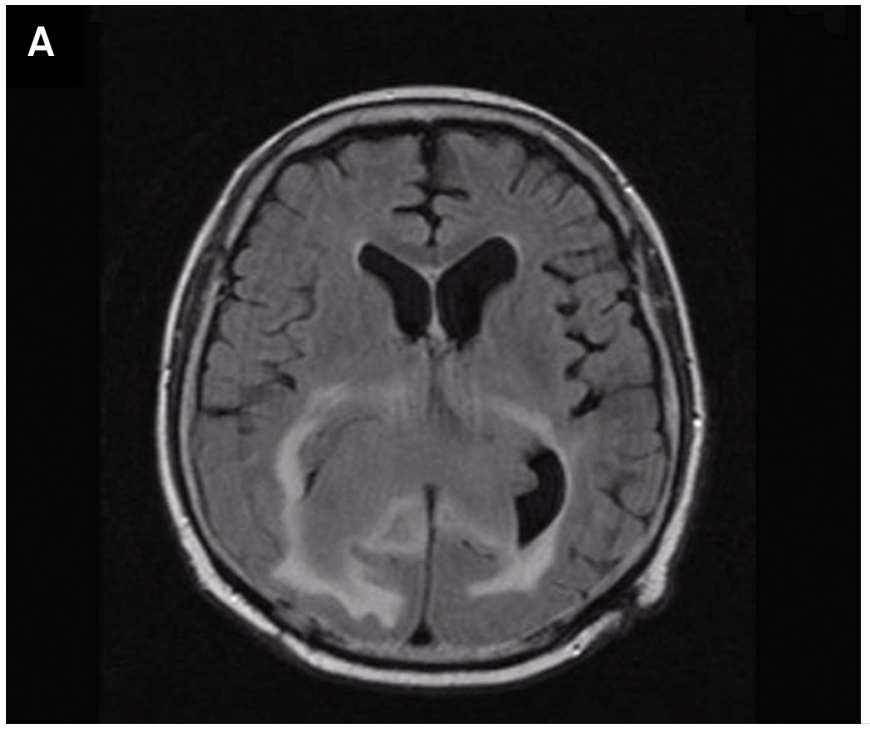

\section{B}

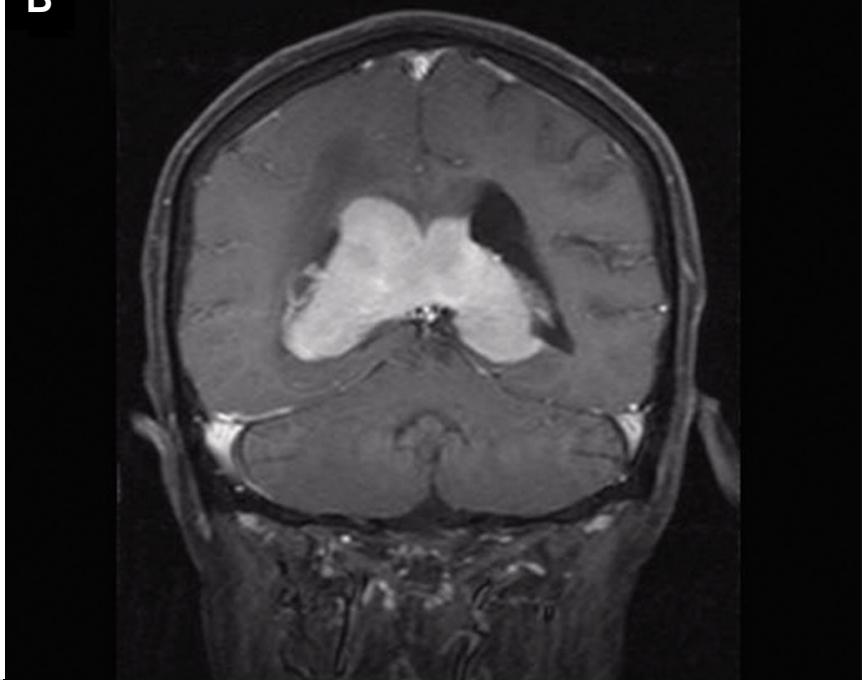

Figure 1. FLAIR sequence (A) showing expansive mass located in the topography of the fornix and splenium of corpus callosum and extending to the lateral ventricles. Presents intense and homogeneous staining in T1 sequence coronal (B).

\footnotetext{
'A. C. Camargo Cancer Center, Departamento de Oncologia Clínica, São Paulo SP, Brasil; ${ }^{2}$ A. C. Camargo Cancer Center, Departamento de Neurologia Clínica, São Paulo SP, Brasil; ${ }^{3}$ A. C. Camargo Cancer Center, Departamento de Patologia Clínica, São Paulo SP, Brasil.

Correspondence: Fernando Freua; Rua Conselheiro Brotero, 1505 / cj 41;01232-011 São Paulo SP, Brasil; E-mail: fernando.freua@hc.fm.usp.br Conflict of interest: There is no conflict of interest to declare.

Received 26 August 2015; Accepted 04 January 2016.
} 


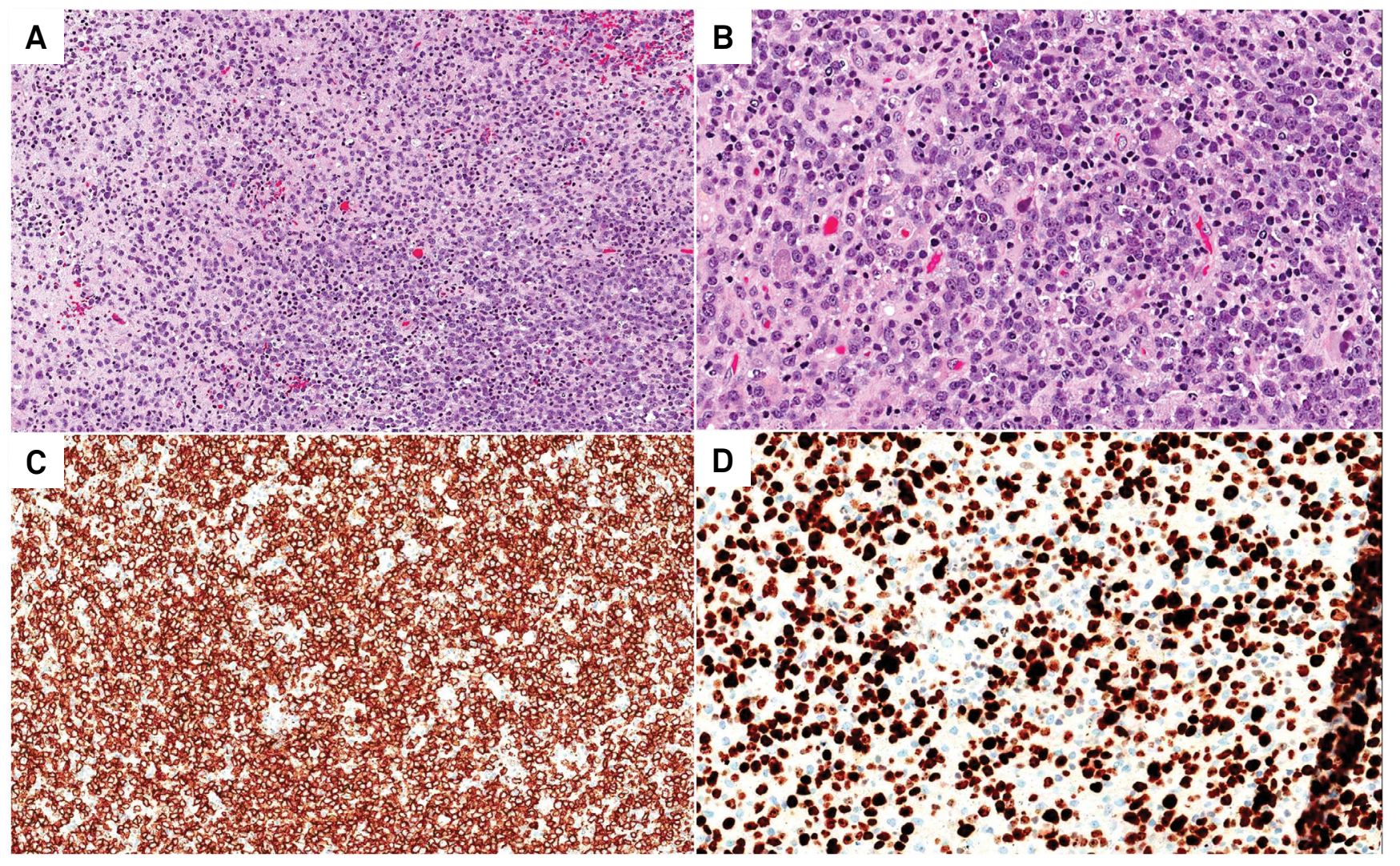

Figure 2. Histologically, the central nervous system parenchyma was diffusely infiltrated by discohesive cells (A, H\&E, 100x). At higher power, the neoplastic cells were round and hyperchromatic, with scant cytoplasm and one or two prominent nucleoli (B, H\&E, 200x). Immunohistochemically, these cells were strongly positive for CD20 (C, anti-CD20 antibody, 100x) with a high proliferative index (D, Ki-67 antibody, 200x). These findings, together with the clinical and radiological data, supported the diagnosis of primary CNS diffuse large B-cell lymphoma.

References

1. Rubenstein J, Ferreri AJ, Pittaluga S. Primary lymphoma of the central nervous system: epidemiology, pathology and current approaches to diagnosis, prognosis and treatment. Leuk Lymphoma. 2008;49(1):43-51. doi:10.1080/10428190802311441
2.

Ferreri AJ. How I treat primary CNS lymphoma.Blood. 2011;118(3):510-22. doi:10.1182/blood-2011-03-321349 